\title{
El amor y las furias: Reflexiones en torno al amor, el maltrato y la violencia en el seno de las relaciones de pareja lesbiana
}

Love and the Furies: Reflections about love, mistreatment and violence inside of lesbian relationships

Angelina Marín Rojas*

\section{Resumen}

El presente trabajo corresponde a una síntesis de parte del tercer capítulo de mi tesina de máster titulada El amor y las furias, segunda etapa de la investigación de continuidad en torno al maltrato y la violencia en el seno de las relaciones de pareja lesbiana, cuya primera fase culminó el año 2009.

Retomando la conclusión de la intersección de diversos sistemas de opresión que se articulan y actúan en el espacio relacional construido por la pareja, fortalecidos y catalizados por la actuación de la lesbofobia social e internalizada, la heteronormatividad y los modelos de amor hegemónicos, estableciéndose como un continuo de discriminación, maltrato y violencia, se profundiza y discute en torno al amor romántico como construcción ideológica y en los mecanismos a través de los cuales viene aprendido, incorporado y suscrito por las mujeres, en particular por las lesbianas.

Palabras clave: Lesbianismo - violencia - feminismo - amor romántico.

\begin{abstract}
This article it is a synthesis of the third chapter of my master thesis entitled "Love and the Furies": the second stage of a research about abuses and violence inside lesbian's relationships, whose first phase was completed in 2009.

In the paper, I retake the thesis' conclusion about the intersection of various systems of oppression that articulate and act on the relational space created by the couple. This mechanism isreinforced and catalysed by the action of the social and the internalized lesbophobia, heteronormativity and hegemonic love models, establishing like a continuum of discrimination, abuse and violence.

Finally I discuss in depth romantic love like an ideological construction and the mechanisms through which is learned, incorporated and signed by women, particularly by lesbians.
\end{abstract}

This work corresponds to a synthesis of the third chapter of my master's thesis titled

* Socióloga, Universidad de Chile. Máster Erasmus Mundus en Estudios de las Mujeres y de Género, Universidad de Granada- Università di Bologna. 
Love and the Furies, the second stage of the investigation of continuity around the abuse and violence within relationships of lesbian couple, whose first phase ended in 2009.

Returning to the conclusion of the intersection of various systems of oppression that articulate and act on the relational space built by the couple, strengthened and catalyzed by the action of social and internalized lesbophobia, heteronormativity and love hegemonic models, establishing itself as a continuum of discrimination, abuse and violence, and discusses deepens around romantic love as ideological construction and the mechanisms through which is learned, built and signed by women, particularly lesbians.

Key words: lesbianism - violence - feminism - romantic love

\section{Introducción}

A principios del año 2009 presenté en la Universidad de Chile mi tesis de grado: Violencia y maltrato al interior de las relaciones de pareja lesbiana: El segundo closet (2009), dando cuenta de un fenómeno complejo e invisibilizado, enmarcado en el continuo estructural de violencia contra las mujeres. Los resultados de dicha investigación evidencian que la comprensión del fenómeno requiere atender a la intersección de diversos sistemas de opresión, que se articulan y actúan en el espacio relacional construido por la pareja, fortalecidos y catalizados por la actuación de la lesbofobia social e internalizada, la heteronormatividad y los modelos de amor, en particular aquel basado en el amor romántico de carácter parejil-familista ${ }^{1}$.

El año 2013 presenté en la Universidad de Granada y la Università di Bologna, una segunda investigación titulada El amor y las furias: Amor romántico en el cine lésbico y su relación con el maltrato y violencia en relaciones de pareja lesbiana a fin de dar, en primer lugar, continuidad a la temática de investigación, profundizando a su vez en algunos conceptos claves; en segundo lugar, abordar y profundizar teóricamente en las nociones de amor, en particular en el amor romántico de carácter parejil-familista, enfatizando en los aspectos ideológicos de dicha conceptualización y en su implicancia en las relaciones de pareja lesbiana; y, finalmente, una discusión y reflexión crítica de las representaciones del amor romántico de pareja y familiar en fuentes cinematográficas con temática lésbica, referenciales en el seno de la llamada cultura lésbica y que conforman lo que podría denominarse un cine lésbico mainstream ${ }^{2}$. El presente artículo

\footnotetext{
${ }^{1}$ Según conceptualización de modelo amatorio parejilfamilista desarrollada por Margarita Pisano.

${ }^{2}$ No profundizo aquí sobre las categorías temática lésbica ni cine lésbico mainstream. Para referencia véase:Marín Rojas, 2013.
} 
constituye una síntesis de parte del tercer capítulo de esta investigación, presentando algunas de las conclusiones de la primera investigación y una profundización en torno al amor romántico como construcción ideológica.

Quisiera señalar, antes de comenzar, que para abordar el maltrato y violencia en las relaciones de pareja lesbiana es ante todo necesario desmontar, desde una mirada lesbofeminista, una serie de presupuestos y estereotipos en torno al lesbianismo, fundamentados en una interpretación del mundo enmarcada en el pensamiento heterosexual (Wittig, 1980/1981)y que, o sugieren la imposibilidad de relaciones de poder entre dos mujeres dadas las características de su género o bien, que las relaciones de poder, en caso de existir, se producen por la adhesión a roles heterosexuales por parte de cada una de las integrantes de la pareja, de modo que una lesbiana masculinizada será activa y violenta per se, como pasiva y no violenta será una lesbiana feminizada, lo cual niega cualquier posibilidad fuera de los roles heteronormados. Estos dos presupuestos han contribuido a la negación e invisibilización de la existencia de relaciones de maltrato en las relaciones lésbicas que alcanzan inclusive al movimiento feminista como a los movimientos LGBTIQ.

Teniendo en cuenta lo anterior, este trabajo pretende ser una aportación para pensar las relaciones amorosas entre lesbianas, las dinámicas de maltrato y violencia que ocurren en su seno y las posibilidades de crear otros paradigmas amatorios, en donde los afectos no compitan entre sí, donde las subjetividades sean libres y autónomas y no sea la aniquilación el único destino.

\section{Ideología Amorosa y Heteronorma}

La heteronormatividad es un entramado complejo que estructura las relaciones sociales que, a fin de mantener la cohesión y estabilidad, requieren de la organización de las emociones, los afectos, los cuidados, a la vez que de las prácticas eróticas y sexuales. Así pues, no sólo hablamos de una práctica sexual buena y una mala o de la jerarquía de valor de las mismas, hablamos también de una pauta, una guía de afectividades, emociones, consecuentes comportamientos y relaciones interpersonales que serán también definidos como correctos y deseables.

Los movimientos feministas, lésbicos feministas y desde hace ya algunos años el queer, han dado cuenta y denunciado el vínculo de las instituciones del matrimonio y la familia patriarcal como parte fundamental del sistema de opresión hacia las mujeres, denunciando a su vez la existencia de una construcción ideológica de los afectos - el amor- que promueve la sumisión de las mujeres a la autoridad masculina (Estado, padre, hermano, esposo, hijo). Dicha posición de sumisión se sostiene mediante la acción de una retórica que "adormece" la capacidad crítica de las mujeres y las convierte no sólo en dóciles súbditas inconscientes de su cautiverio, sino que también en posibles cómplices y colaboradoras del poder heteropatriarcal. La teórica feminista Marcela Lagarde ve, ya en la literatura feminista del siglo XVIII, un profundo análisis 
crítico del amor, siendo el primer aporte revolucionario del feminismo el de "ubicar el amor en la historia" (2001: 19), rechazando de este modo la naturalización del amor y revelando el carácter socialmente aprendido del mismo. El aporte del feminismo viene a desestabilizar la idea de que existe El Amor o,en palabras de Lagarde, implica una crítica a la visión de que "el amor es universal y ahistórico, es eterno, tiene valores universales idénticos y se rige por una moral universal" (Ibíd.).

\subsection{El amor en Occidente: Mito, cortesía y romanticismo ${ }^{3}$}

El amor es una construcción ideológica a la cual se atribuyen una amplia gama de emociones, conductas, prácticas, discursos, símbolos, etc. y que como tales forman parte del aprendizaje social. Implica la reproducción arquetípica de los elementos que incorpora, a modo de un sistema que se retroalimenta y recrea a sí mismo. La construcción ideológica del amor no es única ni universal, está dotada de historicidad, por lo que refleja en sus muchas y diversas expresiones la realidad sociohistórica y geopolítica, tanto como las diversas doctrinas y tradiciones filosóficas con las que convive; así también el amor no es eterno, en tanto que los ideales y valores de los pueblos tampoco lo son.

Denis de Rougemont ve en el amor un fenómeno histórico con un marcado referente en la construcción ideológica del amor cortés, cuyo carácter es fundamentalmente religioso. A modo de ejemplo, en el popular mito de Tristán e Isolda, señala, se oculta la doctrina de los Cátaros quienes veían en la renuncia a la materia una vía de purificación, conocimiento y acceso a la salvación. Es en los valores de dicha doctrina que se construye la retórica del amor cortés, donde el objeto y relación de adoración deben permanecer sin mácula que les corrompa, estableciendo un vínculo entre amor y pasión, relacionada esta última ineludiblemente con el sufrimiento, con la desgracia asociada al abandono a la materialidad y al cuerpo, es decir, la corrupción de lo sacro. El amor pasión es el amor mortal, "amenazado y condenado por la propia vida" (Rougemont, 2010:16), del cual emergen los ideales del amor cortés donde el obstáculo, la desgracia y el sufrimiento significan una ascesis ${ }^{4}$ que encuentra su mayor expresión en la muerte, superación radical del obstáculo de la materia y la posibilidad del encuentro en la Unidad.

La poesía, el "lenguaje del amor", género que en Europa encuentra algunos de sus exponentes fundamentales en los trovadores, para Rougemont no es otra cosa que "la exaltación del amor desgraciado" (ibíd.: 77). La poesía de los trovadores cuenta con una retórica y un sistema fijo de leyes - las leysd'amors- con las que se construye el relato del "amor perpetuamente insatisfecho" (ibíd.). Este amor no apela al matrimonio, sino

\footnotetext{
${ }^{3}$ Tomaré como principal referente en este punto el trabajo de Denis de Rougemont (2010; 1939), quien dedicó gran parte de su vida a escribir y revisar su obra El amor y occidente, en la que realiza una exhaustiva revisión de mitos Europeos y en particular del popular mito de Tristán e Isolda.

${ }^{4}$ El concepto de ascesis refiere al seguimiento metódico de reglas, prácticas y desprendimientos necesarios para alcanzar la virtud y la liberación del espíritu de las trabas de la materia y el cuerpo.
} 
más bien lo cuestiona en su limitación meramente funcional y material, siendo la unión deseada aquella que está más allá de los límites mundanos de la vida. Ahora bien, tal como con un objeto de adoración sacro, la ritualidad es relevante, apunta el autor, siendo fundamental el "domnei o donno ${ }^{5}$, vasallaje amoroso" (ibíd.: 78), mediante el cual se accede a la gracia a través del homenaje y la ofrenda de servidumbre.

Las raíces místicas y paganas del Roman comienzan a desaparecer a partir del siglo XIV; sin embargo, su retórica permanece, volviendo material a la mujer y dirigiendo el amor a una versión idealizada de ella, que la mantiene "inaccesible en su jardín escarchado de alegorías [...] El obstáculo ${ }^{6}$ a la unión amorosa está representado por la exigencia moral, y ya en modo alguno religiosa: ya no es una ascesis mística, sino un refinamiento del espíritu, que debe llevar al amante a merecer el don" (ibid:78).

El romanticismo es para Rougemont la vulgarización y democratización del mito, en donde la pasión se ha convertido en un derecho que no es más que "vaga obsesión de lujo y de aventuras exóticas" (ibíd.: 238) totalmente ajena a una ascesis. Numerosos cuentos infantiles famosos hasta nuestros días ponen en evidencia la existencia de dos fuerzas en conflicto, por una parte la burguesa y por otra la romántica, respondiendo a lo que Rougemont llama "influencia anarquizante de la pasión" (ibíd.: 239). Por una parte, la inclusión de la lógica del mérito transforma la relación romántica en una relación de carácter económico, a la cual todos pueden acceder en virtud de su esfuerzo, coincidiendo con el advenimiento de doctrinas filosóficas que promueven la lógica del trabajo y los bienes materiales como un camino de salvación en la Tierra. La mujer es un premio concreto que se traduce en alianzas y estatus, donde por supuesto la idea de consentimiento no tiene ninguna importancia.

Pero el burgués moderno ya no desea la muerte, dice Rougemont, sino que requiere conciliar "[el] deseo de que nada se arregle y [el] deseo de que todo se arregle; deseo romántico y deseo burgués" (ibid:.240-241), para lo cual se ha valido - sobre todo en el cine- de la figura estilística del happyend, el cual constituye una acción radical que resuelve rápida y eficazmente el conflicto de deseos mediante la supresión oportuna del obstáculo y la cancelación estratégica de la imaginación hacia el futuro: manos unidas, un beso, una imagen "que compense la decepción del romántico ante el alivio del burgués" (ibid:241).

El amor romántico no sólo instala y reproduce una lógica de meritocracia de los afectos, conectada con los valores -y deseos- de la burguesía y el capitalismo, sino que también se convierte en un exitoso producto del sistema económico, a la vez que en relevante promotor de sus valores, en tanto que exalta la propiedad privada, la división social y sexual del trabajo, la entrega gratuita del trabajo reproductivo y de cuidados, la idea de movilidad social a través de la acumulación y el mérito. Como "producto especializado del capital" (Esteban, 2011: 106), el amor romántico vende su pasión a través de los diversos medios culturales y de comunicación, a través de la publicidad, de bienes materiales, rituales, cenas, viajes, etc., todos catalogados como "románticos".

\footnotetext{
${ }^{5}$ Cursiva en el original.

${ }^{6}$ Cursiva en el original.
} 
¿Cuáles serían las transformaciones, adaptaciones o correcciones ideológicas necesarias para la subsistencia del amor romántico en el capitalismo neoliberal? Si el modelo capitalista exalta la propiedad privada, la competencia y la meritocracia, éstas debieran adaptarse y volverse superlativas en un modelo de carácter neoliberal, lo que implica abrir los mercados a la participación de todos los agentes que actúan, buscando alcanzar el mayor beneficio - en virtud de su audacia y mérito-, y desde la gestión privada crear un universo de oportunidades que, aunque impliquen grandes sacrificios como el endeudamiento, den la posibilidad al audaz de alcanzar la gloria. ¿Significa esto que la construcción ideológica del amor romántico se abre a la participación de nuevos sujetos, por ejemplo las lesbianas? ¿Qué pruebas deben pasar estos nuevos sujetos? ¿Cuál es la gloria?

\subsection{Un amor conducente a la aniquilación}

La noción de amor para Rougemont está en principio asociada a la búsqueda de sufrimiento, relacionada a su vez con la noción de mujer contenida dentro del popular mito de Tristán e Isolda, la idea de "sufrimiento fecundo ${ }^{7}$ que halaga o legitima oscuramente, en lo más secreto de la conciencia occidental, el gusto por la guerra" (ibid:247); esto queda en evidencia tanto por el lenguaje guerrero del amor como por el uso de metáforas bélicas que reproducen las ideas de conquista, estrategias de combate, tácticas militares y triunfo sobre la mujer. Si el lenguaje del amor es privado de su relación mística, se convierte en un relato de fuerza cuya ascesis es totalmente material, aquella de los derechos adquiridos por las leyes de la guerra y la conquista, y por lo tanto, con una concepción androcéntrica de la sociedad en la que prevalece el derecho del mejor guerrero, más allá de las voluntades y de la verdad ${ }^{8}$.

El mito de Tristán e Isolda narra una épica donde los amantes se ven involucrados involuntariamente y les envuelve la fuerza arrolladora de la pasión. El encuentro de los amantes sucede por la acción de un encantamiento, un filtro de amor - por error bebido- que permite "describir una pasión cuya violencia no puede ser aceptada sin escrúpulo" (p.49). El encantamiento después de tres años desaparece y la cordura retorna, de modo que cada quién se verá enfrentado a tomar el camino que se le ha señalado de acuerdo a su género y rango. El arrepentimiento opera como una posibilidad de redención, pero si la añoranza de la pasión lleva a buscar formas de revivirla, el destino será el sufrimiento, una vida de penitencia para alcanzar la redención. Pero el objetivo del mito es la ascesis, señalar el camino de la virtud y liberación del espíritu, que, en su versión original, debe redimir tanto la falta como el hecho de haber nacido en el mundo de las tinieblas, el mundo de lo material: el cuerpo y la vida en este mundo son el más grande obstáculo y la muerte el mayor triunfo.

La acción del filtro de amor, convertida románticamente en fatalidad amorosa, introduce

\footnotetext{
${ }^{7}$ Cursiva en el original

${ }^{8} \mathrm{Ej} .:$ los duelos de honor.
} 
desde mi visión, en primer lugar, la idea de finitud de la pasión amorosa: tres años, que corresponden a la duración del filtro; en segundo lugar, la legitimidad de una búsqueda permanente de la emoción de la pasión, un deseo de sufrimiento sin unidad en la muerte; $y$, en tercer lugar, la idea de intercambiabilidad del objeto de amor, es decir, la idea de una mujer intercambiable (Rougemont, 2010:30; Guiducci, 1977: 27) y que en su reemplazo deviene inmutable. Una búsqueda eterna de Isoldas, una búsqueda que se rebela a la idea monógama de fidelidad masculina donde no es posible la traición, pues Isolda es una idea, que sólo toma forma una vez tocada por el caballero (Sánchez Espinoza, 2006). La pasión es un camino hacia la gloria, pero una de la cual Isolda(s) no participa(n) salvo mediante la fortuna de haber sido alcanzada por la pasión del caballero.

En la ópera Tristan und Isolde de Wagner, basada en el homónimo mito medieval, se representa, en gran parte del Acto II, la tragedia de los amantes incapaces de trascender al obstáculo del cuerpo mediante un encuentro nocturno furtivo donde se lamentan de la existencia de la conjunción "und" ("y") que separa sus nombres. Pero la desaparición del "und" vinculante es insuficiente para alcanzar la "verdadera felicidad" pues, mientras permanezca el nombre, la individualidad, no será posible el encuentro en la Unidad, por lo que es necesario renunciar inclusive a la individualidad, renunciar inclusive a aquello que se respeta y admira: “[...] iEs necesario que el otro deje de ser el otro, y por tanto que ya no sea, para que deje de hacerme sufrir y que sólo haya "Yo-elmundo"9!" (Rougemont, 2010: 313.). Esta ansiedad fuera del sentido místico no es más que una búsqueda de asimilación de la subjetividad del otro u otra, a la subjetividad del uno o una, en definitiva: la aniquilación.

La construcción ideológica amorosa cortés y romántica revelan en su retórica una interpretación del mundo en un eterno binario: una separación original radical que enfrenta en polos opuestos toda la realidad, pero que en su conflicto pareciera recordar a un estado unitario perdido; una interpretación polar del mundo en eterno conflicto de absolutos $^{10}$, donde la fuerza del deseo de cada una de las partes, es lo que mantiene el equilibrio del universo. En él se enfrentan la noche y el día, el sol y la luna, que representan principios irreconciliables cuya única posibilidad de encuentro pareciera ser siempre la aniquilación simbólica de uno (como en el caso de los eclipses de luna y sol) o ambos. El obstáculo, cumple en la retórica romántica la función de señalar la separación ("und", "/"), por lo tanto, mientras más grande e insalvable el obstáculo, mayor la pasión. Si el más grande obstáculo es la muerte, su transgresión es el motivo de mayor gloria pues "el hombre creado, que pertenece a la Noche, no puede encontrar la salvación más que dejando de ser y "perdiéndose" en el seno de la divinidad" (ibid:69).La tragedia de la pasión, en un sentido místico, permite la superación momentánea de lo que divide y la participación fugaz en una Unidad divina, por lo que los amantes "se sienten arrebatados "más allá del bien y del mal" en una especie de trascendencia de nuestras comunes condiciones, en un absoluto indecible, incompatible con las leyes del mundo, pero que experimentan como más real que este mundo" (ibid:40).

\footnotetext{
${ }^{9}$ Cursiva en el original.

${ }^{10}$ Bien/Mal, Masculino/Femenino, Guerra/Paz, Sacro/Profano, Vida/Muerte, etc.
} 
El romanticismo alemán, señala Rougemont, expresa el mito dando cuenta de una relación dialéctica entre los principios que componen, en su forma más elemental, lo que he llamado eterno binario. Esta dialéctica, de origen maniqueo, viene a significar que: "El mismo impulso que llevaba el alma hacia la luz y la unidad divina, considerado desde el punto de vista de este mundo no es más que el impulso hacia la muerte, una separación esencial" (p. 226).

¿Y si es el camino de la razón ilustrada la nueva ascesis? ¿Y si el burgués ilustrado no desea renunciar ni al deseo ni a la pasión? Es pues la guerra lo que resta en la retórica amorosa, la fuerza, la apropiación violenta de la subjetividad del otro que en su otredad encadena; por medio de la violencia de la conquista se reedita la pasión que lleva a la liberación, que no es más que amor a sí mismo y deseo asimilación de la otredad, que en caso de resistirse deberá ser conquistada por la leyes de la guerra: La violación a manos de Don Juan o la muerte a manos de Sade (ibid:215-219), imperio o guerra (ibid:265-269).

\subsection{La construcción ideológica del amor romántico}

El análisis del mito amoroso evidencia un ideal construido sobre base negativa, donde confluyen la tragedia, la pasión y la muerte, porque "[e]l amor feliz no tiene historia. Sólo el amor mortal es novelesco" (Rougemont, 2010:16). La retórica amorosa repite una y otra vez la fórmula "iniciación, pasión, cumplimiento mortal" (p.234) ocultando mediante la idealización amorosa el gran misterio de su complicidad con la muerte, un misterio que no queremos admitir. Esta gran contradicción amorosa es posible por el carácter ideológico de la construcción del amor: "[...] El amor como lo sublime y el amor como engaño, no se afectan, no se invalidan entre sí, sino que se entienden como perfectamente compatibles" (Esteban, 2011: 53).

Así, como dice Margarita Pisano "el amor viene mal nacido" (2004b: 93-95), está basado en un modelo de sufrimiento: la eterna carencia; un incompleto esencial que, en el ideal de amor enseñado actualmente, sólo es posible de resolver mediante la acción de otro $\mathrm{u}$ otra que se posee o nos posee. Un amor que no es más que exaltación de un yoindividual que no ama al otro - ama la idea de amor- sino que además desea su aniquilación en sí mismo; un amor que ha transformado en retórica a los sujetos de amor y les ha simplificado en el "caballero" y la "princesa". En estas condiciones: "¿Cómo concebir un afecto humano entre dos tipos simplificados de esta manera?" (Rougemont, 2010: 41).

La simplificación de los sujetos, la contradicción entre lo sublime y el engaño, la alegría y la muerte segura, insisto, sólo son posibles de concebir dado el carácter ideológico del amor romántico. El amor romántico no es un mito, es un constructo ideológico específico que exalta la negatividad como camino a la trascendencia, valiéndose para ello de una retórica y un espectro de representaciones que cumplen una fórmula 
narrativa ${ }^{11}$ específica donde el obstáculo y la superación del mismo, cobran centralidad. La clave negativa del amor romántico se basa en la pasión que no es otra cosa que desgracia, un suicidio, una clave ideológica que instala y exalta "la escasez, no la abundancia. El encarcelamiento y no la libertad. Una muere siempre de alguno de estos males: duelen lo mismo, matan lo mismo" (Pisano, 2004a: 66-67).

Conceptualizar el amor romántico como un mito o como un conjunto de mitos, ubica al amor en un espacio de irrealidad fabulosa, mágica e irracional, omitiendo las implicancias políticas, materiales y simbólicas del amor, a la vez que se irracionalizan e irresponsabilizan los discursos y prácticas de quienes en su nombre cometen atrocidades y vejaciones de todo tipo.

Si bien las construcciones ideológicas cortés y romántica comparten la clave negativa de su retórica, no comparten sus ideas de trascendencia; mientras una observa la trascendencia en la unidad divina por medio de la moderación y la castidad, la construcción romántica trasciende en vida material y alcanza la gloria en una forma equivalente a la victoria militar. Por supuesto, en ambas construcciones la mujer tendrá un rol diverso; en la primera representa la divinidad, la pureza y debe ser adorada, mientras que en la segunda debe ser conquistada. Coincido con Mari Luz Esteban cuando describe al amor romántico como:

[U]n tipo de ideología cultural [...] que incita a la búsqueda de la trascendencia, incluso de la felicidad, a través del amor, y se convierte así en la modernidad en un sustituto de la religión; que vincula la pasión a la tragedia y la muerte, y otorga el máximo valor a cualquier proceso amoroso que implique superar dificultades; que idealiza la relación e hipertrofia la parafernalia amorosa(2011: 44)

El amor romántico expresa una determinada ideología de género en la cual los roles son diferenciados, respondiendo a un binario que ubica "hombre/mujer" en posiciones no sólo antagónicas, sino que también en total desequilibrio. Mientras el amante transita "de puerto en puerto", ella se mantiene fija en su espera, porque la representación de la mujer, aunque vinculada a la divinidad, carece de movilidad, salvo de la mano de un interventor masculino: el padre o el héroe. Mientras la retórica romántica enseña a los hombres la guerra, la conquista, la aventura, el valor del mérito y la competencia, a las mujeres les enseña la necesidad de prepararse para convertirse en un objeto deseable de ser conquistado, pues el único modo de sobrevivir en sociedad -de acuerdo a los ideales sujetos "simplificados" del romántico- es que las mujeres dediquen su vida a "enseñar a sus hijas los trucos para sobrevivir dentro del patriarcado, haciéndose gratas y uniéndose a hombres poderosos o económicamente solventes"12 (Rich, 1973: 136). Mujeres de merecer, hombres merecedores.

La mujer es construida como "el otro" cuya diferencia inquietante es suprimida, permitiendo así el mantenimiento del orden y la exorcización de los miedos más

\footnotetext{
${ }^{11}$ Obstáculo>Encantamiento>Pasión>Fin del encantamiento>Superación total y/o cancelación del obstáculo. Véase Marín Rojas, 2013.

${ }^{12}$ AdrianneRich analiza aquí el libro Women and Madness de Phyllis Chesler.
} 
profundos - la pérdida y la muerte- y, dando cuenta a su vez del deseo humano de reincorporación tanto a la unidad como al universo (Monticelli 2007: 67-82). Sin embargo, en el amor romántico no basta la construcción de la mujer como "el otro" para la subsistencia del "yo-el-mundo", es necesario, tal cual lo ha hecho el Dios, el control sobre la otredad radical, su asimilación en la propia y única subjetividad.

El amor romántico y su modelación amatoria es "masculinista en esencia" (Pisano, 2004a: 66) y, en consecuencia, su realización en la construcción de pareja "está patriarcalizada en el dominio" (ibíd.: 66). Así también su retórica, sus representaciones, su visión del mundo, son los de la dominación masculina (Bourdieu, 2012) que "convierte a las mujeres en objetos simbólicos" (ibíd.: 86). Este no-ser autónomo se encuentra ubicado por efecto de la dominación en un "estado permanente de inseguridad corporal o, mejor dicho, de dependencia simbólica" (ibíd.:86). El amor romántico se pretende a su vez como una "configuración emocional e identitaria, la romántica, que jerarquiza las distintas interacciones amorosas", de modo que "su pasión" "entra en tensión con otros tipos de amores, lo que posibilita a su vez la consolidación de un determinado orden social, desigual" (Esteban, 2011: 44). Pero ante todo es heterosexual, siendo la plenitud sólo posible por la acción del otro heterosexualmente normado pues, ideológicamente requiere de la conformación binaria de las relaciones; en consecuencia, "implica no sólo privilegiar una forma de deseo frente a otras posibles, sino una forma de entender las relaciones entre lo masculino y lo femenino absolutamente dicotómica y complementarista" (ibid:48).

Así pues, las narrativas y discursos del amor romántico dan por sentada la heterosexualidad y reproducen la idea de que la tensión heterosexual es fundamental para la existencia y reproducción de la sociedad (Rich, 1980; Wittig, 1980).

\section{Pensamiento Amoroso y Modelos Amatorios}

El amor romántico como construcción ideológica forma parte de una particular concepción del mundo, de la vida, de las relaciones sociales e interpersonales, que exalta la idea del mérito y la acumulación para alcanzar la gloria, lo que no sólo hace referencia a los afectos sino que a todos los aspectos de la vida, instalando una lógica de competencia permanente. Sin embargo, en tanto que el romántico exalta la pasión de carácter más bien anómica, el amor requiere articularse con otras construcciones ideológicas que "canalicen su comportamiento", entre las cuales se encuentran otras ideologías y modelos amorosos que tienen por fin estructurar no sólo la sexualidad, sino también los afectos, los cuidados y los vínculos entre las personas, de acuerdo a la norma social, es decir, patriarcal y heteronormada, androcéntrica y adultocéntrica, sexista, clasista, racista, misógina y homo/lesbo/trans fóbica.

El pensamiento amoroso ${ }^{13}$ (Esteban, 2011) como articulación alcanza e influencia todos los espacios sociales e institucionales y, en consecuencia directa, las prácticas de la

${ }^{13}$ Conjunto articulado de símbolos, nociones y teorías en torno al amor. 
gente, "estructurando unas relaciones desiguales de género, clase y etnia, y un modo concreto y heterosexual de entender el deseo, la identidad y, en definitiva, el sujeto" (ibíd.: 23). Según Esteban, el pensamiento amoroso, como ideología cultural, comparte con el amor romántico la pretensión de prevalencia por sobre otras emociones, afectos, valores o facetas humanas; por ejemplo el amor familiar ${ }^{14}$ puede prevalecer sobre la justicia o la alegría; oel amor de pareja sobre la verdad. El pensamiento amoroso implica también "una representación y una organización concreta del parentesco, de la familia, del matrimonio, construcciones que van todas a la vez" (ibíd.: 48). Por lo tanto, el pensamiento amoroso es histórico, cultural e ideológico y, señala Esteban, serán unas determinadas coordenadas las que lo producen y consolidan.

De la articulación en el pensamiento amoroso emergen modelos y sistemas amatorios (Pisano, 2004b) que estructuran la orientación y la práctica amatoria dirigiéndola a ciertos sujetos y/u objetos en vez de a otros. Estos modelos son aprendidos ya no sólo a partir de una retórica, narrativa y representaciones particulares, sino también a través de una ritualización, cuyo ejercicio dura toda la vida (Esteban, 2011: 50), promovida por un amplio y extenso aparataje cultural de relatos, imágenes, juegos, canciones, fiestas, etc. La ritualidad corresponde a la práctica de una determinada performatividad amorosa (ibíd.: 51) que imita las referencias y representaciones del aparataje cultural mencionado, a la vez que lo articula con las referencias provenientes de espacios de socialización como la familia y la escuela. La performance amorosa y los rituales son fundamentales para la consolidación y reproducción de los modelos amatorios, configurándose como mecanismos de integración y participación social en tanto que forman parte de una concepción de mundo "compartida" en el mejor de los casos; por fuerza, hegemónica, en la mayoría.

Las construcciones ideológicas que se articulan en el pensamiento amoroso se aplican diferenciadamente para hombres y para mujeres, se aplican según la heteronorma; del mismo modo sucede con el amor romántico y su performance amorosa, en la que se simplifica diferenciadamente a los sujetos, correspondiendo a la mujer la representación de la eterna espera y al hombre la eterna conquista: "la princesa" y "el caballero". Si pensamos en afectividades no heterosexuales cabe retomar y replantear la pregunta de Rougemont ${ }^{15}:$ ¿Cómo se puede concebir un afecto humano entre dos mujeres o dos hombres simplificados de esa manera? ¿Cómo se puede concebir un afecto no heteronormado entre sujetos que han nacido, crecido $y$ aprendido el amor de esta manera? ¿Cómo se puede concebir un afecto entre dos mujeres formadas en la espera y la desolación?

\subsection{La idealización romántica}

Uno de los elementos que conforma la retórica del amor romántico es la idealización del mismo, de sus dinámicas relacionales - el momento del encuentro, el

\footnotetext{
${ }^{14}$ Que ya implica en la mayoría de los casos definiciones heteronormadas y burguesas de familia.

${ }^{15}$ ¿Cómo se puede concebir un afecto humano entre dos sujetos simplificados de esa manera?
} 
enamoramiento o la pasión y la muerte (o en su defecto el happyend)- y de los sujetos de amor.

La primera y principal de todas las idealizaciones es aquella de El Amor en sí mismo, que convierte al amor en un "sentimiento y experiencia sublime" (Esteban, 2011: 52-53), de modo que aunque sea vivido de forma dolorosa y terrible, es mágicamente asociado a felicidad, se tiene "el deber" de ser feliz ${ }^{16}$. La idea del amor como "el mayor de los sublimes" es lo que hace que tenga centralidad y prevalencia frente a otros aspectos de la vida de las personas, pues le otorga el carácter de "lo más genuino del ser humano, el motor por excelencia" (ibíd.: 53).

La segunda idealización está relacionada con la carencia, con el miedo, el miedo a los otros y el miedo a la soledad, y corresponde a la idea de que el amor es un refugio donde las personas se encuentran a salvo de la orfandad permitiendo una "verdadera" realización del sí mismo (Esteban, 2011; Lagarde, 2012, acceso online: 10/08/2013). La idea de refugio es construida diferenciadamente para hombres y para mujeres, constituyéndose el hombre en el "protector" de la mujer que ha sido a su vez educada en el miedo, la dependencia y la creencia de que nunca está completa, plena por sí misma (Pisano, 2004b; Lagarde, 2012). Si para las mujeres los hombres son el sosiego, para los hombres las mujeres deben ser el "descanso del guerrero" a la vez que amantes complacientes de los deseos del caballero-soldado. La idea del amor como refugio por una parte exalta una idea androcéntrica de virilidad que impone a los hombres un "deber ser" patriarcal, que les obliga a ser "fuertes y valerosos caballeros" a la vez que un "eficientes proveedores"; mientras que a las mujeres exige una extraña pero por siglos entrenada- mezcla entre madresposas, virgen-monja, putas, hijas y esclavas $^{17}$ (Lagarde, 2011).

Otra idealización amorosa ubica la experiencia y la simbólica del amor dentro del ámbito de lo irracional (Rougemont, 2010: 49, Pisano, 2004b: 94; Esteban, 2011: 53), de modo que las decisiones y los actos cometidos en su nombre están desprovistos de razón y como consecuencia, desprovistos de conciencia y responsabilidad. La irracionalidad es central en la ideología romántico amorosa, "perder la cabeza" ${ }^{18}$ es una de las condiciones del romántico, una medida del amor. Así, en tanto que se "recupera la cabeza", se "sienta cabeza", se termina la acción del filtro, se pierde el amor. Bajo el amparo de esta idea se han cometido - y se seguirán cometiendo- miles de crímenes "de amor".

De la articulación de estas tres principales idealizaciones amorosas románticas -sublime, refugio, irracional- derivan un sin número de idealizaciones que tanto tienen que ver con la experiencia concreta del amor, como con la percepción de la realidad del vínculo y la sanidad del mismo. También derivarán idealizaciones y distorsiones asociadas a cada uno de los sujetos que participan de la relación amorosa romántica y, que les

\footnotetext{
${ }^{16}$ Es la dialéctica de base negativa que se ha expuesto con antelación.

${ }^{17}$ Categorías que desarrolla Lagarde en Los cautiverios de las mujeres.

18 ... y el cuerpo, agregará Pisano. Perderse entera precisaría yo, para no mantener en el lenguaje la estructura del eterno binario.
} 
comprometen a determinados comportamientos y performatividades: "una parafernalia amorosa hipertrofiada" (Esteban, 2011: 44).

Las nociones de propiedad, territorio, celos, dolor, angustia, miedo, ahogo, muerte, cobran en la construcción romántica un sentido positivo, puesto que son la "prueba" de que se está efectivamente "enamorado". Estas nociones se encuentran asociadas en el significado al deseo de asimilación de la subjetividad alterna como un modo de asegurar su control y al deseo de fusión aniquilante en el "Yo-el-mundo", porque "las proyecciones de propiedad sobre otra persona son las formas de buscar finalmente nuestras seguridades" (Pisano, 2004b: 185), un modo de resolver el miedo de orfandad (Lagarde, 2012). En la misma línea se encuentra la idea de fidelidad amorosa, siendo el reconocimiento explícito, la ruptura del tabú, de que el amor romántico está basado en el dominio, en la relación amo/siervo.

El dolor, la angustia, el miedo, el ahogo, la muerte son positivas en la dialéctica de la negatividad, que sugiere que aquello más deseado es, precisamente lo que lleva a la perdición. Todas estas emociones, sensaciones y símbolos, están relacionadas con el miedo: a no encontrar, no reconocer, a que no dure, a que se vaya, que no retorne, que se pierda, que se apague, que escasee, que se acabe... El Amor. Porque, como faceta humana ideológicamente prevalente, El Amor se pretende cómo único y eterno, lo cual nos lleva a la idea romántica del "amor de la vida", el "verdadero amor", único e irrepetible, que aunque fracasado permanece como huella indeleble y reconocible para las próximas experiencias que deberán "conformarse con lo que ha quedado".

\subsection{El modelo amatorio romántico parejil-familista}

De la articulación en el pensamiento amoroso (Esteban, 2011) de diversas construcciones ideológicas, símbolos, nociones y teorías en torno al amor emergen modelos amatorios (Pisano, 2004a/b), que estructuran y orientan la práctica amatoria, estableciendo marcos y pautas de comportamiento en relación con las diversas dimensiones y espacios de la vida social. Los modelos amatorios son a su vez socio-geohistóricos y por lo tanto se encuentran relacionados con la particular sociedad, cultura y tiempo en el que se desarrollan y, valga la redundancia, responderán a las ideologías hegemónicas del contexto.

En consecuencia, los modelos amatorios serán diversos y diversamente entenderán, agruparán, clasificarán, regularán y jerarquizarán, por una parte (al menos), idealización, erotismo, intimidad y durabilidad; por otra, la interacción entre los individuos y el parentesco (Esteban, 2011). Así, en una sociedad basada en la supremacía de algunos sobre otros, los modelos amatorios serán en consecuencia jerárquicos: heteronormados, clasistas y racistas. $Y$, puesto que responden a una base ideológica fundamentada en un eterno binario, serán también modelos pares, es decir, en pareja. 
Margarita Pisano (2004a) plantea que las mujeres nos encontramos atrapadas en un modelo amatorio que además de romántico es parejil y familista ${ }^{19}$, cuya profundidad y asentamiento en el simbólico es de tal modo hegemónica, que tiene la capacidad de recuperar para sí las experiencias afectivas que intentan subvertir la heteronorma. Según este modelo, la experiencia amatoria tiene sólo un camino: la pasión amorosa, la pareja y la familia, y todas las relaciones debieran conducirse del mismo modo. En esta "religión amorosa" la unidad divina se alcanza en la pareja, en el matrimonio, y la trascendencia, en la familia. Es el triunfo final de una particular visión de la trascendencia, posible sólo a través de la comunión Sujeto/Religión/Estado: la trinidad.

El modelo parejil-familista está a su vez idealizado, atribuyéndosele características que de per se no posee: "no es comprensivo, honesto, fiel ni tampoco un lugar de derechos humanos. Todas estas condiciones las tienen o no las personas por sus valores y creencias culturales" (Pisano, 2004b: 93-94), porque si nuestra socialización "mujeres" es en la dominación, en un no ser que se materializa a través del ser masculino, no es posible una relación de horizontalidad, porque la base es el dominio.

Este modelo impulsa a las mujeres a la pareja, la convivencia, el matrimonio, y bajo este mismo se sostienen los imperativos relacionados con la maternidad y la familia. La articulación del romántico, la pareja, el matrimonio, la maternidad y la familia es posible mediante el espacio vacío del happyend que le sitúa "[...] en el mundo del matrimoniofamilia-consanguinidad con su proyección de fidelidad para toda la vida" (Pisano, 2004b: 94). Es el definitivo alivio del burgués frente a la incertidumbre romántica.

Así como el amor implica una felicidad obligada, no ser parte del modelo implica el supuesto de infelicidad, carencia, in-completitud ${ }^{20}$ e imposibilidad de trascender. Por ello, indica Pisano, "ante esta perspectiva la gente se queda aferrada a una pareja por el miedo de transitar por estas soledades, que expresan - para lo establecido - el sin sentido del vivir [...] un ser solo, sin pareja establecida, empieza a ser un apartado" (2004b: 94).

Pero el modelo amoroso romántico parejil-familista fracasa siempre o casi siempre (Bosch et al. 2004-2007), porque "viene mal nacido y en estas condiciones es el lugar de la violencia, física, intelectual y psicológica. [...] es el gran espacio de las decepciones y las ilusiones nunca alcanzadas" (Pisano, 2004b: 95). Pero no es sólo una desgracia, es también tremendamente peligroso para las mujeres, porque han sido socializadas en la dominación masculina, que les lleva a creer que sólo por la intervención del amor proveniente de un otro-pareja-masculino, con quien se constituye pareja y familia (y se vive feliz para siempre...), cobra sentido la vida (Bosch et al. 2004-2007). Así, el amor deviene un elemento estructural de la feminidad (Esteban, 2011: 107) que convierte a las mujeres en una identidad trágica: "alguien que espera" (Ibíd.). Y, "aunque todas las mujeres no aspiren a encontrar un hombre rico o ni siquiera se sientan atraídas por hombres, y/o estén satisfechas con sus propios proyectos, sí siguen fantaseando (muchas) con alguien que está en algún lugar esperándolas. O más bien ellas esperan"

\footnotetext{
${ }^{19}$ Conceptualizaciones acuñadas y desarrolladas por Margarita Pisano.

${ }^{20}$ La palabra incompletitud no existe en el diccionario RAE sin embargo si existe completitud referido a la cualidad de completo, por este motivo se ha separado con un guión del prefijo negativo in.
} 
(Ibíd.).

Uno de los mayores riesgos de este modelo amatorio es su valoración distorsionada de la dificultad y el riesgo, pues ve en ellos las pruebas del amor. El amor redime al pecador, al maltratador; el amor salva al perdido y al condenado; porque el amor es devoción y pertenencia; porque el amor resiste a todas las dificultades; porque "contigo a pan y cebolla"; porque "con sangre de mis venas te marcaré la frente, para que te respeten y sepan que tú eres mi propiedad privada" ${ }^{21}$. Este amor no es más que "el deseo de tener-poseer para completarse" (Pisano, 2004b: 95), puro deseo egótico, puro deseo capitalista, pura violencia; y, la presencia permanente y continua de su retórica en los diversos medios culturales - literatura, música, cine, publicidad - no hace más que reproducir y recrear el modelo, extendiéndolo y eternizándolo al infinito (Bosch et al. 2004-2007).

\section{El Segundo Closet}

Hace años que el movimiento lésbico feminista denuncia y busca problematizar desde una perspectiva política el maltrato y la violencia en las relaciones de pareja lesbiana. Sin embargo, el fenómeno continúa siendo invisibilizado y silenciado pues, en primer lugar, en torno a él se articula un complejo entramado de prejuicios que niegan su existencia basándose en los roles y estereotipos que derivan de la construcción de género heteronormada (Tron, 2004; Marín Rojas, 2009); en segundo lugar, por la invisibilización y aislamiento de las parejas lésbicas, consecuencia de la discriminación y la lesbofobia, social e internalizada, (Sardá, 1996; Viñuales, 2002; Falquet, 2006; Marín Rojas, 2009); y, por último, por las dificultades "estratégicas" que implica para ciertos sectores del movimiento LGBTI centrados en la lucha por el matrimonio y la adopción, pues enturbia las posibilidades de aceptación al relacionar a la pareja no heterosexual con comportamientos violentos socialmente indeseables (Marín Rojas, 2009).

El programa argentino Desalambrando aborda el maltrato y la violencia entre lesbianas desde el año 2002, un tema que en Latinoamérica, dadas las condiciones de discriminación y exclusión hacia las personas no heterosexuales, fortalecidas entre otros factores por el imperio de las dictaduras y su herencia, ha sido relegado y visto dificultades para su debate y reflexión. Pese a lo anterior, gracias a Desalambrando y a la insistencia y compromiso de diversas activistas se ha logrado generar e iniciar la sistematización del conocimiento y reflexiones en torno al fenómeno, comenzando a hablarse del Segundo Closet (Eiven, 2006; Marín Rojas, 2009) dada su similitud con la situación de ocultamiento, encierro, invisibilización, negación y angustia (como falta de aire) que viven las personas no heterosexuales al verse forzadas, por temor o seguridad, a no revelar su orientación diversa, siendo este el primer closet.

Salir del closet ${ }^{22}$ implica una serie de riesgos para las lesbianas: el rechazo del entorno

\footnotetext{
${ }^{21}$ Del vals peruano "Propiedad Privada", de Modesto López Otero.

${ }^{22}$ Salir del armario, coming out.
} 
social significativo, la violencia, la marginación, la ridiculización y la discriminación, son algunos de ellos. Sin embargo, salir del segundo closet implica, primero, una ruptura con las expectativas de refugio, salvación y paz, creadas en torno a la pareja y que se sustentan en los ideales del amor romántico y el modelo amatorio hegemónico de tipo parejil-familista; segundo, implica asumir los problemas con la pareja y entrar en tensión con una compartida comunidad lésbica constituida como espacio de acogida, aceptación y seguridad que tiende (por los motivos ya expuestos) a negar, silenciar o invisibilizar la existencia de maltrato y violencia; tercero, pone en riesgo la seguridad del secreto de una lesbianidad no reconocida en los espacios de interrelación social y; por último, el mayor riesgo: la incredulidad, fundamentada en los estereotipos y roles de género que asignan a lo femenino la suavidad y la pasividad (Marín Rojas, 2009).

La investigación que presenté el año 2009 habla de las características que constituyen el contexto social, político y personal de quienes conforman pareja, donde se promueven y articulan la lesbofobia, la heterosexualidad obligatoria, los modelos de poder basados en el género, el modelo de amor basado en la perpetuidad de la pareja y la familia y que constituyen un marco continuo de discriminación, maltrato y violencia, enmarcado a su vez en el continuo estructural de violencia contra las mujeres. Afirmar que la violencia y el maltrato se enmarcan en un continuum ${ }^{23}$ de violencia hacia las mujeres señala tanto el carácter estructural de la misma como enfatiza en que los hechos de violencia, maltrato y discriminación no están aislados entre sí, sino que se encuentran articulados e intersectan con otros sistemas de opresión. Una salida real del segundo closet requiere ir a la base del mismo, es decir cuestionar y deconstruir la realidad que sostiene los mencionados continuos.

Cuando hablamos de violencia y maltrato al interno de una pareja lesbiana no estamos necesariamente y/o exclusivamente hablando de aquella ejercida por parte de una de las componentes hacia la otra o viceversa ${ }^{24}$, hablamos de un sistema particular donde el continuo queda en evidencia mediante la articulación de la discriminación, lesbofobia, misoginia, invisibilización y otras formas de privilegio y poder que construyen la opresión y la subordinación ${ }^{25}$. No se trata sólo de un contexto o una historia de violencia, sino de una estructura basada en la desigualdad y en la sanción de cualquier intento de subversión, mediante mecanismos de culpabilización, marginación y exclusión, de los cuales el maltrato y la violencia forman parte. Esta estructura se sostiene a partir de constructos ideológicos que dan origen a modelos de afectividad, sexualidad, familia y comunidad.

No pretendo con esto victimizar a las lesbianas ni exculpar a quienes ejercen violencia por el hecho de ser parte de un colectivo discriminado. Mi intención es señalar que, si la violencia es un continuo estructural, son necesarias ciertas claves que la legitimen como forma de ejercicio y perpetuación del poder, que legitimen a su vez los sistemas jerárquicos de poder y, mecanismos de culpabilización que lleven a quienes la padecen a

\footnotetext{
${ }^{23}$ La noción de la violencia como un continuum fue desarrollada por Liz Kelly en 1988. Utilizo durante todo el texto la palabra castellana continuo.

${ }^{24}$ En la primera investigación se rechaza la idea de la existencia de un maltrato y violencia mutua y equivalente. Véase Marín Rojas 2009.

${ }^{25}$ Racismo, clasismo, privilegios coloniales, territoriales y otros.
} 
aceptarla como legitima sanción a sus transgresiones. Esas claves encuentran su lugar en la construcción ideológica del amor.

Como se ha dicho, abordar el maltrato y la violencia en relaciones lésbicas significa ir a la base que estructura las desigualdades, cuestionarla y deconstruirla, afrontando a su vez las particularidades que implica el pertenecer a un colectivo excluido como lo es el de las lesbianas, sin perder de vista la articulación de los diversos sistemas de opresión con la construcción ideológica hegemónica del amor. Según mi investigación del año 2009 dicha articulación está presente en distintos niveles y ámbitos de la biografía de las lesbianas, sea en un nivel estrictamente individual, de pareja y/o colectivo, como opresiones, reconocidas o no, que se vivencian como provenientes de un externo, pero también como prácticas y discursos que se reproducen hacia sí mismas, a modo de un continuo de discriminación, maltrato y violencia. Éste es, en sí mismo, un elemento de conflicto en la medida que la relación y experiencia individual con él puede establecer jerarquías de poder diversas basadas, por ejemplo, en la visibilidad, redes, aceptación familiar y otras.

Para ilustrar lo anterior, operacionalizo tres ámbitos de la experiencia biográfica personal de las lesbianas -individual identitario, social contextual y relacional (Marín Rojas, 2009)- interrelacionados circularmente entre sí, en cada uno de los cuales el continuo es confrontado e internalizado como modelo de sufrimiento proyectable tanto hacia otras lesbianas como hacia sí mismas y que, en tanto experiencia vital, está presente en la construcción de pareja lésbica, cerniéndose como una amenaza al amparo de la construcción ideológica romántico amorosa parejil-familista. En cada uno de estos ámbitos son fundamentales los procesos de asumirse ${ }^{26}$ lesbiana y de salir del closet $^{27}$, pues implican una puesta en tensión de la heteronorma y un enfrentamiento material y simbólico de las sanciones asociadas a su transgresión. Asumirse y salir del closet no son procesos con principio y fin, sino que se retorna permanentemente a ellos, en tanto que las experiencias personales y los espacios social-simbólicos se modifican. Al ser procesos continuos y en constante revisión, son relevantes en la construcción de relaciones amorosas lésbicas, pues en ellas es necesario acordar la gestión de los procesos individuales en relación con los espacios sociales significativos, sean estos familiares, de amistad, formación, trabajo u otros, donde la norma heterosexual se manifiesta explícitamente y sanciona. El enfrentamiento permanente de la heteronormatividad atraviesa todos los espacios de la vida como un imperativo particularmente coercitivo sobre las mujeres y por tanto sobre las lesbianas, debido a que su autonomía y autodeterminación es más ampliamente negada y su vida, pública y privada, su afectividad, cuerpo y sexualidad son objeto de mayor control.

Así, el continuo se manifiesta de formas diversas, desde el exterior y también desde el interior, articulándose de múltiples modos con la ideología amorosa, tensionando a la

\footnotetext{
${ }^{26}$ Proceso que implica el reconocimiento personal e íntimo de atracción, orientación o preferencia sexual hacia personas del mismo sexo, a la vez que el proceso de reconocimiento de las consecuencias personales, sociales y políticas de no adherir totalmente a la heteronorma (Véase Marín Rojas, 2009).

${ }^{27}$ Proceso de tránsito del ámbito privado al ámbito público donde se explicita la orientación o preferencia sexual hacia las personas del mismo sexo. Puede hacer diferenciación de espacios sociales, separando aquellos donde la salida es efectiva de otros en los que en muchas ocasiones se observa un comportamiento que no "levante sospechas".
} 
pareja al tiempo que actúa como el obstáculo de la narrativa romántica, dotando a la relación de la necesaria épica dolorosa propia del modelo.

En el ámbito individual identitario ${ }^{28}$, relacionado con el proceso autorreflexivo e individual de asumirse, la pareja enfrenta tensiones necesarias de gestionar, tales como la proyección de la culpa lesbofóbica" ${ }^{29}$ la introyección de la lesbofobia, el "grado" de asumida $^{30}$, la asociación de valor del ser lesbiana y la dificultad para nombrarse.

A estas tensiones sobre la pareja, propias de la acción e internalización del continuo, se suman aquellas que emergen del dar a conocer la orientación sexual o preferencia al entorno emocional y socialmente significativo: ámbito de la experiencia social contextual; relacionado con el proceso de salir del closet, lo que se produce en diversos niveles de relación, intensidad y publicidad. En este ámbito el continuo toma múltiples formas, entre las cuales se encuentran: la obligación al "ghetto" para manifestar afecto; la doble vida; la necesidad de dinero para asistir a lugares "gayfriendly", miedo a las agresiones lesbofóbicas; miedo a la pérdida de la fuente de ingresos por motivos lesbofóbicos y la reducción de las redes de apoyo ${ }^{31}$, son algunas.

En un tercer nivel, el del ámbito de la experiencia relacional, relacionado con los procesos de conformación de relaciones afectivas, eróticas y sexuales con personas del mismo sexo - no necesariamente relaciones de pareja ni duraderas-, "realizando" el deseo y confrontándolo al de un/a otro/a diverso, se acumulan nuevas tensiones que interactúan sinérgicamente con las otras, convirtiendo a la pareja en un espacio de riesgo, un espacio romántico. Entre estas tensiones encontramos: soledad y dependencia de la pareja; precipitación de la convivencia ${ }^{32}$; miedo a no representar el mismo atractivo sexual que un hombre; adecuación de la relación a modelos tradicionales con el fin de obtener aceptación; amistades en común; negación y ocultamiento de la relación; entre otras.

Como se ha dicho, las tensiones son expresiones del continuo de discriminación, maltrato y violencia que afecta a las lesbianas $y$, por lo tanto, operan a modo de controles heteronormativos. Los controles heteronormativos comprenden desde la omisión en el lenguaje de las alternativas sexuales distintas a la heterosexual, a la discriminación y la amenaza social, limitando de este modo no sólo los espacios de relación sino que las posibilidades de supervivencia, sea en términos económicos (trabajo) y de acceso a derechos (salud, educación, etc.), como en la reducción de las redes de apoyo, solidaridad y cuidados.

La misoginia, la discriminación y la lesbofobia son formas de violencia social que no sólo se experimentan individualmente, sino que afectan y tensionan la construcción de

\footnotetext{
${ }^{28}$ Los ámbitos y sus tensiones se encuentran ilustrados gráficamente a modo de mapas de tensiones acumuladas. Véase: Marín Rojas, 2009; 2013.

${ }^{29} \mathrm{Si}$ la otra no existiese no se sería lesbiana.

${ }^{30}$ Jerarquía que algunas lesbianas establecen sobre el cuánto se reconoce y se "es" lesbiana.

${ }^{31}$ El ocultamiento de ciertos aspectos de la vida a personas que conforman la red de apoyo es uno de los efectos críticos de la lesbofobia social e internalizada en tanto que genera y profundiza el aislamiento, el encierro de a dosy por tanto las relaciones de dependencia afectiva, emocional y económica en la pareja.

${ }^{32}$ Se agudiza en casos en los que la lesbofobia social obliga a la huida de alguna de las partes.
} 
relaciones afectivas, inclusive las de amistad. En el caso de las relaciones de pareja lésbica la violencia estructural las hace más proclives al aislamiento social, al encierro de a dos (Falquet, 2006) y a la dependencia, en tanto que la pareja constituye la única red de apoyo (Marín Rojas, 2009). Del mismo modo los modelos de afectividad de carácter romántico promueven idearios en torno a la pareja en los que, sin aparente contradicción, confluyen tanto la salvación, la contención y el refugio frente a la hostilidad lesbofóbica, como los celos y la propiedad sobre la otra persona (Marín Rojas, 2009).

Los modelos de afectividad son heteronormados y regulados en sus posibilidades de ejercicio. En el caso de las relaciones afectivas en las cuales la sexualidad esté involucrada, ésta sólo es aceptada en el caso de que se ajuste a lo promovido como bueno y sano: heterosexual, en pareja, intramatrimonial, con fines reproductivos, intrageneracional, etc. (Rubin, 1989). Quienes cumplen con todos o la mayoría de los requerimientos y prácticas sexuales heteronormativas gozan de ciertos privilegios, siendo el más importante de todos, la legitimidad social de sus prácticas. El imperativo heterosexual, el modelo amatorio hegemónico y su pulsión hacia el establecimiento de la pareja única y para toda la vida, forman parte de la estructura dentro de la cual se conforman las relaciones amorosas lésbicas y que, con el fin de obtener parte de la esquiva aceptación, reconocimiento y legitimidad social, adscriben a valores heteronormados, heterosexualizados, binarios y jerarquizados.

Cabe preguntarse: si el modelo es heteronormado y heterosexual, si está basado en las jerarquías y el dominio, si es un modelo que se sostiene en el miedo, el maltrato y la violencia ¿cómo y por qué las lesbianas suscribimos a él?, ¿es acaso una suscripción instrumental basada en la búsqueda de legitimidad y garantías de derechos?, ¿o es más bien que este modelo penetra particularmente en las lesbianas en tanto que socializadas como mujeres y viene luego adaptado a la propia realidad?

\section{Reflexiones finales}

El capítulo de la investigación que da origen a este artículo parte de la premisa de que el sistema heteronormado, que es heterosexista, misógino, racista y clasista, se vale de distintos mecanismos para sostener su hegemonía, en la cual las mujeres carecen de una subjetividad propia más allá del deseo masculino. A partir de éste, sostengo como una de las principales conclusiones el carácter ideológico del amor romántico, el cual se modifica continuamente según los contextos sociales, geográficos, históricos y políticos en los que se desarrolla. Siendo así, en una sociedad capitalista neoliberal, por lo tanto heteronormada, los valores que encarna el amor romántico son los del capitalismo neoliberal: la propiedad privada y la meritocracia.

Vinculado a lo anterior, sostengo que el modelo amatorio promovido en dicho sistema es parejil y familista, mediante el cual se estructuran heteronormativamente las relaciones de afecto, solidaridad y cuidados tanto como el erotismo y las prácticas 
sexuales, estableciendo una jerarquía de vínculos que privilegia, simbólica, material y legalmente, un cierto tipo de relaciones por sobre otras, como podrían ser por ejemplo las relaciones de amistad. En este contexto, la desobediencia y la disidencia vienen normalizadas y adecuadas a los intereses de un sistema que reproduce su lógica binaria de jerarquía y poder no sólo sobre las lesbianas, las mujeres y otras desobedientes, sino también sobre todos los seres humanos y la naturaleza en su conjunto.

En efecto, la representación de la afectividad lésbica en el cine ${ }^{33}$ y la literatura, está basada en la construcción ideológica del amor romántico, la cual es en esencia de carácter heteronormativa, generando pautas relacionales e imaginarios afectivos que exaltan la negatividad, el sufrimiento, la muerte y la aniquilación como parte fundamental y necesaria del amor. En dichas representaciones no sólo "se representa" sino que también se difunde, promueve y perpetúa el amor romántico parejil-familista como un modelo de afectividad deseable para las lesbianas. En el caso del cine, las películas de temática lésbica se valen de la estructura narrativa romántica, cuya retórica de dialéctica negativa es resuelta mediante la suscripción al modelo amatorio hegemónico. A partir de esto, afirmo que esta estrategia tiene por fin servir a la heteronormalización y recuperación por parte del sistema neoliberal de las lesbianas, como sujetos desobedientes o disidentes frente al imperativo heterosexual, convirtiéndolas en agentes cómplices del mantenimiento y reproducción del sistema.

Sin embargo, pese a la oferta de legitimidad social que significa la suscripción al modelo amatorio parejil-familista, esta no resuelve el continuo de discriminación, maltrato y violencia que afecta a las lesbianas, por el contrario lo refuerza, pues les orienta a un tipo de relación permanentemente amenazada por la lesbofobia social e internalizada. Lo anterior, asociado a la pulsión hacia el deseo de establecer pareja según la idealización romántica de refugio, el deseo de terminar con la marginalización, el deseo de propiedad y el miedo a la pérdida, tensionan el espacio relacional convirtiéndolo en un escenario fértil para la emergencia de dinámicas de maltrato y violencia en su seno. La narrativa romántica lésbica culmina siempre en la conformación de la pareja, omitiendo, cancelando, la omnipresencia terrorista de la heteronorma, al tiempo reforzando los contenidos ideológicos de la construcción del amor romántico parejilfamilista.

La promesa de felicidad eterna del amor romántico parejil-familista es no sólo una falacia, sino también un peligro para las mujeres y las lesbianas. Sin embargo y pese a todo, las lesbianas adherimos, pues la heteronorma constituye un obstáculo tan omnipresente como la materialidad del cuerpo, de modo que la promesa romántica de superación de aquello que separa y margina constituye en muchos casos un anhelo real, porque el continuo es real. Pero como el amor (tramposamente) feliz es romántico, parejil y familista, no sólo tendemos a adherir a él, sino que además permanecemos, aunque nos haga profundamente infelices, porque como lesbianas "debemos ser felices" dentro de este modelo, porque es el que otorga el acceso, aunque sea mínima y efímeramente, al tan ansiado mundo de los privilegios del sistema heteronormado.

El continuo de discriminación, maltrato y violencia está en el centro de la construcción

${ }^{33}$ Véase Marín Rojas, 2013 
ideológica romántica parejil-familista. Luchar contra él implica cuestionar y avanzar en la desconstrucción de la base ideológica que sostiene y perpetúa al amor romántico, su modelación amatoria neoliberal y el conjunto de imaginarios, expectativas, dependencias y realidades que de ella derivan.

La investigación que da origen a este artículo tiene como uno de sus resultados relevantes el desarrollo y profundización de un marco para la reflexión en torno al amor romántico, el maltrato y la violencia en el seno de las relaciones de pareja lesbiana. Este artículo da cuenta de dicho marco, en un contexto de casi total ausencia de literatura e investigación en torno al tema, debido a la invisibilización de la existencia lesbiana, la negación de la existencia del maltrato, la idealización del amor lesbiano y, por supuesto, a los énfasis que el financiamiento da al desarrollo de investigación. El presente es, por lo tanto, una invitación y una provocación al desarrollo de investigación y estudios lésbicos, al debate, la reflexión y la acción tendientes al cuestionamiento y deconstrucción de los modelos hegemónicos de afectividad, a la vez que un desafío a la necesidad de profundizar y perseverar en la lucha política radical contra toda forma de discriminación, maltrato y violencia. 
Bibliografía

Bosch, Esperanza et al. (2004-2007). Del mito del amor romántico a la violencia contra las mujeres en la pareja. Universidad de les Illes Balears.

Bourdieu, Pierre (2012) La dominaciónmasculina. 7ma edición. Trad. de Joaquín Jordá, (2000). Barcelona:Anagrama.

Eiven, Laura (2004) "Infierno y discriminación o paraíso y diversidad". Ponencia presentada en el Foro de salud sexual: Los paraísos de la sexualidad, infierno y discriminación o paraíso y diversidad. 25 de Marzo, Buenos Aires, 2004. Disponible en: http://www.mujeresaloeste.org.ar/lesbianismo/2004/12-11.html

-- (2006) "Por los pliegues de la violencia doméstica entre lesbianas. Abriendo el camino para salir del segundo closet". Ponencia presentada en el 1er Encuentro nacional de la diversidad sexual de las mujeres. 13, 14 y 15 de Octubre, Bogotá, 2006. Disponible online en: http://www.desalambrandobsas.org.ar/pdf/textos/Eiven laura.pdf

Esteban, Mari Luz (2011) Crítica del pensamiento amoroso. Barcelona: Colección Temas contemporáneos, Ed. Bellaterra.

Falquet, Jules (2006) "La pareja este doloroso problema: Hacia un análisis materialista de los arreglos amorosos entre lesbianas." En Falquet, J.: De la cama a la calle: perspectivas teóricas lésbico-feministas. Bogotá: Brecha Lésbica-Ed. Antropos.

Flores, Valeria (2004) “ $i C o n$ las valijas afuera! Un aporte para pensar el maltrato entre lesbianas", en web Desalambrando, Buenos Aires [On Line]. Disponible en: http://www.desalambrandobsas.org.ar/pdf/huellas voces/valijas.pdf

Guiducci, Armanda (1977) “Introduzione” a: Rougemont, D (1977;1939). L'amore e I'Occidente, traducción italiana de Luigi Santucci. Milano: Rizzoli.

Juliano, Dolores (2010) "Excluidas y marginales: Una aproximación antropológica". Tercera edición. Colección Feminismos, 1ㅇe ed. 2004. Valencia: Ed. Cátedra, Universitat De Valencia, Instituto de la Mujer.

Lagarde, Marcela (2001) "Claves feministas para la negociación en el amor". Managua: Ed. Managua: Puntos de Encuentro.

(2011) "Los cautiverios de las mujeres. Madres, esposas, monjas, putas, presas y locas”. Primera publicación 1990. Madrid: Ed. horas y HORAS 2011.

(2012) "La Soledad y la Desolación". [On Line] en: www.mujerpalabra.net

Marín Rojas, Angelina (2009) "Violencia al interior de las relaciones de relaciones de pareja lesbiana: El segundo closet". Tesis de Sociología, Santiago de Chile. Universidad de Chile. 
(2013) "El amor y las furias: Amor romántico en el cine lésbico y su relación con el maltrato y violencia en relaciones de pareja lesbiana". Tesina de Máster Erasmus Mundusen Estudios de las Mujeres y de Género, Universidad de Granada, España; Università di Bologna, Italia.

Monticelli, Rita (2007) "Amnesie, afasie, (in)dicibilità del primitivo". Artículo en: GOLINELLI, G. Il primitivismo e le sue metamorfosi. Archeologia di un discorso culturale. CLUEB, 2007, Bologna, pp. $67-82$.

Pisano, Margarita (2004a) El triunfo de la masculinidad.Santiago de Chile: Ed. Surada (2004b) Julia, quiero que seas feliz. Santiago de Chile: Ed. Surada.

Rich, Adrianne (1973) "Jane Eyre: Las tentaciones de una mujer sin madre" en: Rich, A. Sobre mentiras, secretos y silencios. Madrid: horas y HORAS, la editorial. 2010, pp.:133-156.

(1980): "Heterosexualidad obligatoria y existencia lesbiana". Trad. MariaMilagros Rivera Garretas. De Adrienne Rich, Compulsory Heterosexualityand Lesbian Existence, en Ead., Blood, Bread, and Poetry. Selected Prose1979- 1985. Nueva York y Londres: Norton, 1986,23-75." Ed. original en Revista Signs1980.

Rougemont, Denis de (2010; 1939) El amor y occidente. 10ma edición. Trad. de Antoni Vicens (1979). Barcelona: Ed: Kairós.

Rubin, Gayle(1989) "Reflexionando sobre el sexo: Notas para una teoría radical de la sexualidad", en Vance, C. (comp.): Placer y peligro. Explorando la sexualidad femenina.Madrid:Ed. Revolución.

Sánchez Espinosa, Adelina (2006) "Diosas a la carta para artistas decadentes: una lectura feminista de TheWell-Beloved" en Carretero, M. et al. Eds.: De Habitaciones propias y otros espacios conquistados. Estudios sobre mujeres y literatura en lengua inglesa en homenaje a Blanca López Román.Granada:Universidad de Granada.

Sardá, Alejandra (1996): “Lesbofobia Internalizada”. Comisión Internacional de DD.HH de Lesbianas y Gays. Disponible enhttp://potenciatortillera.blogspot.it/1996/05/lesbofobia-

internalizada.html.Traducción y Adaptación del original de: LIPSKY, Suzanne (1987) "InternalizedRacism". Seattle: Rational Island Publishers. Disponible en: http://www.nypolisci.org/files/PDF\%20FILES/Chapter\%20IV \%207 \%20internaliz ed\%20racism.pdf

Tron, Fabiana (2004) "Violencia en relaciones íntimas entre lesbianas: Una realidad invisible". Ponencia presentada en el Encuentro Entre Nosotras, Rosario, Argentina. $2004 . \quad$ Disponible en: http://www.desalambrandobsas.org.ar/pdf/textos/tron fabiana.pdf

Viñuales, Olga (2002) “Lesbofobia”. Barcelona: Ed. Bellaterra. 
Wittig, Monique (1980) "El pensamiento heterosexual". Artículo en Wittig, M. (1992) El pensamiento heterosexual y otros ensayos. Trad. Javier Sáez y Paco Vidarte. Barcelona: Egales, pp.45-57.

(1981) "No Se Nace Mujer". Artículo en Wittig, M. (1992) El pensamiento heterosexual y otros ensayos, trad. Javier Sáez y Paco Vidarte. Barcelona:Egales, pp.31-43.

Fecha de Recepción: 30 de julio del 2014

Fecha de Aceptación: 11 de julio del 2015 